\title{
Meniscus Shape and Wetting Competition of a Drop between a Cone and a Plane
}

\author{
Yu-En Liang, ${ }^{\text {a }}$ Yu-Hsuan Weng, ${ }^{a}$ Heng-Kwong Tsao,,${ }^{\text {b,c, }}$ Yu-Jane Sheng ${ }^{\text {a, }}$ \\ ${ }^{a}$ Department of Chemical Engineering \\ National Taiwan University, Taipei, Taiwan 10617 \\ ${ }^{\mathrm{b}}$ Department of Chemical and Materials Engineering \\ National Central University, Jhongli, Taiwan 32001 \\ ${ }^{c}$ Department of Physics
}

National Central University, Jhongli, Taiwan 32001

Corresponding authors :

Heng-Kwong Tsao, hktsao@,cc.ncu.edu.tw

Yu-Jane Sheng, yjsheng@,ntu.edu.tw 
SE

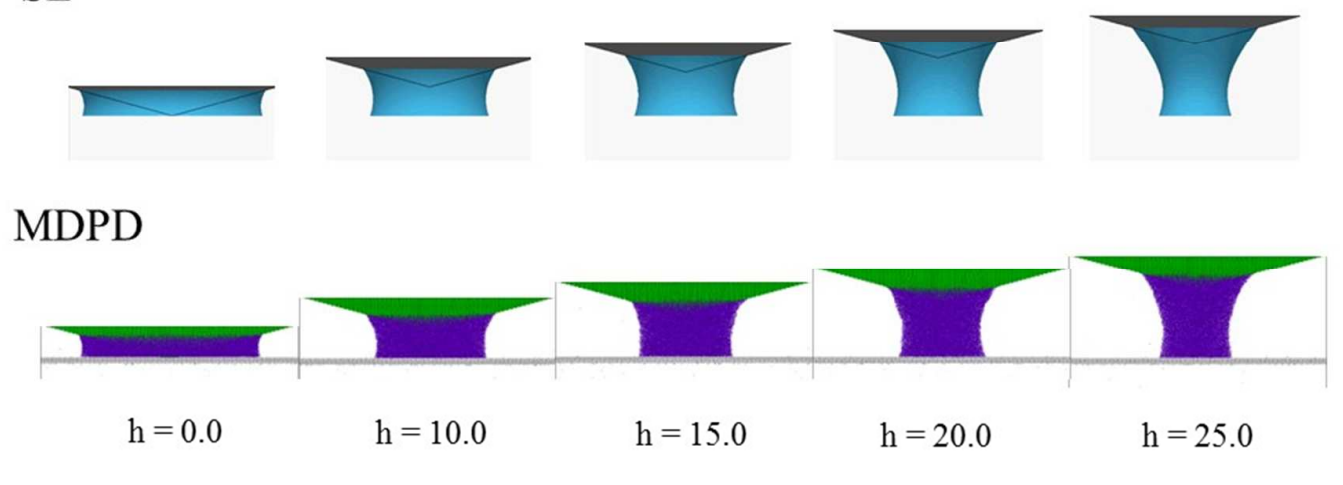

Figure S1 (a). The comparison of the shapes of the meniscus between SE and MDPD $\theta_{\mathrm{P}}=70^{\circ}$ and $\theta_{\mathrm{C}}=40^{\circ}\left(2 \alpha=150^{\circ}\right)$

SE

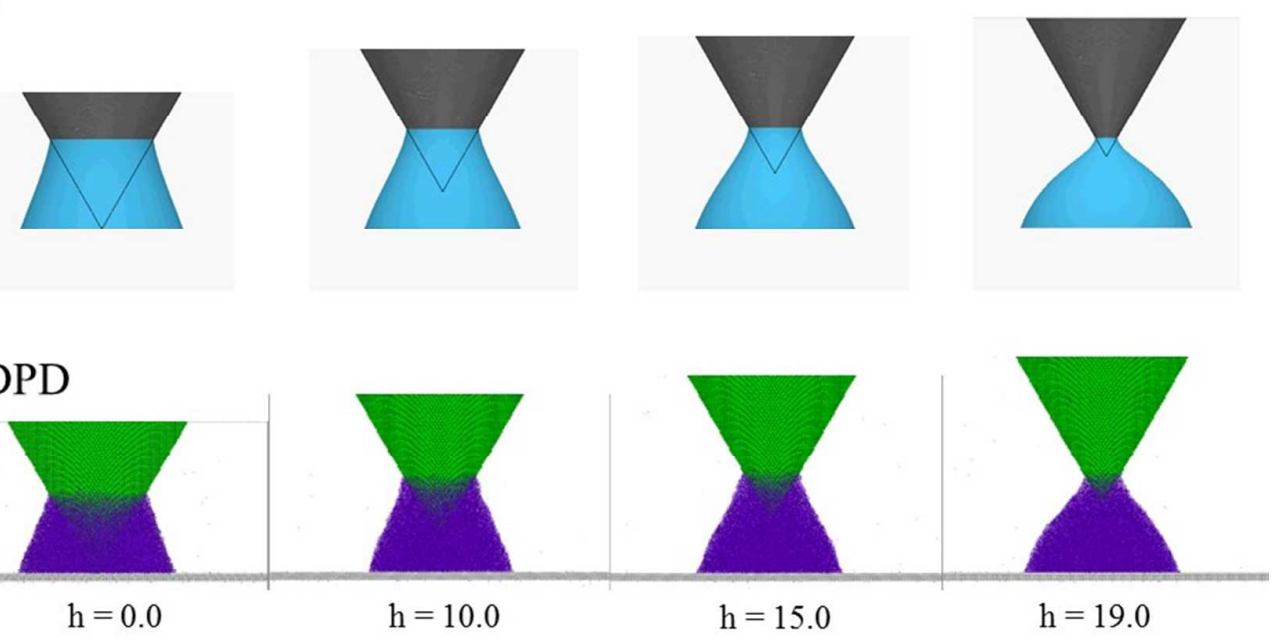

Figure S1 (b). The comparison of the shapes of the meniscus between SE and MDPD $\theta_{\mathrm{P}}=70^{\circ}$ and $\theta_{\mathrm{C}}=40^{\circ}\left(2 \alpha=60^{\circ}\right)$ 